\title{
Association of physical activity on body composition, cardiometabolic risk factors, and prevalence of cardiovascular disease in the Korean population (from the fifth Korea national health and nutrition examination survey, 2008-2011)
}

Gwang-Sil Kim ${ }^{1}$ Eui $\mathrm{Im}^{2}$ and Ji-Hyuck Rhee $\mathrm{e}^{2,3^{*}}$

\begin{abstract}
Background: Data regarding associations among physical activity (PA) level, body composition, and prevalence of cardiovascular diseases in Asian populations are rare.

Methods: The International Physical Activity Questionnaire (IPAQ) was utilized to estimate PA levels and analyze the association of PA level with various body composition parameters and the prevalence of cardiovascular diseases by using data from the Korean National Health and Nutrition Examination Survey from 2008 to 2011.

Results: Moderate and high PA levels were associated with lower prevalence of hypertension and diabetes mellitus, and lower concentrations of serum ferritin, parathyroid hormone, and alkaline phosphatase. Sarcopenia (low vs. moderate vs. high PA group: $14.3 \%$ vs. $10.5 \%$ vs. $7.3 \%, p=0.001)$, underweight ( $5.7 \%$ vs. $4.9 \%$ vs. $3.5 \%, p=0.001)$, and central obesity ( $7.8 \%$ vs. $6.9 \%$ vs. $6.3 \%, p=0.002$ ) were more often observed in the low PA group. The prevalence rates of cardiovascular diseases were lower in the moderate (odds ratio [OR], 0.822; 95\% confidence interval [CI], 0.737-0.916; $p=0.001$ ) and high activity groups $(\mathrm{OR}, 0.663 ; 95 \% \mathrm{Cl}, 0.589-0.748 ; p=0.001)$ than in the low activity group, even after adjusting for age, sex, smoking, underlying disease, and general or abdominal obesity and muscle mass.
\end{abstract}

Conclusion: Regular physical activity was associated with a low prevalence of cardiovascular diseases (stroke, myocardial infarction, stable angina, and chronic renal disease), which was independent of body composition and conventional risk factors in the Korean population, with a positive dose-response relationship.

Keywords: Cardiovascular disease, Obesity, Sarcopenia, Physical activity

\footnotetext{
* Correspondence: RJH54112@yuhs.ac

${ }^{2}$ Division of Cardiology, Department of Internal Medicine, Yongin Severance

Hospital, Yonsei University College of Medicine, Yongin, Republic of Korea

${ }^{3}$ Division of Cardiology, Yongin Severance Hospital, Yonsei University College

of Medicine, 225 Geumhak-ro, Cheoin-gu, Yongin 17046, South Korea

Full list of author information is available at the end of the article
} 


\section{Background}

Cardiovascular disease (CVD) is the leading cause of death and disability worldwide. According to World Health Organization global estimates of mortality and burden of disease, $30 \%$ of all global deaths were associated with CVD $[1,2]$. Besides increasing mortality, CVD leads to substantial health-care expenditures and decline in economic growth due to decreased work activity and permanent disability [3]. CVD is a multifactorial disease process influenced by various biological and behavioral characteristics. Smoking cessation, physical activity (PA), weight reduction, and healthy diet are the major components of an effective CVD prevention program [4]. These lifestyle modifications are a proven cost-effective strategy for both primary and secondary prevention of CVD [5-8].

Regular PA clearly decreases the risk of CVD at the same magnitude as that of smoking cessation [9-11]. Previous reports documented that the median risk reduction for CVD was about 40\% when comparing between most and least active subjects. These results persisted even after adjusting for traditional cardiovascular risk factors such as hypertension (HTN), dyslipidemia, and diabetes mellitus (DM) [12, 13]. Based on this evidence, the federal government issued its first-ever PA guidelines for Americans in 2008 [14].

However, relatively few studies have examined the relationship between PA level and coronary heart disease/ CVD risk in nonwhite populations [15]. Moreover, only few studies have simultaneously demonstrated the association among PA level; clinical measures of body composition such as waist circumference (WC), muscle mass, or body mass index (BMI); and the prevalence of CVD.

Therefore, this study was conducted to assess the relationship of PA level as defined by the International Physical Activity Questionnaire-short form (IPAQ-SF) [16] with body composition and prevalence of CVD by analyzing data from the fifth Korean National Health and Nutrition Examination Survey (KNHANES) conducted from 2008 to 2011.

\section{Methods}

\section{Study population}

In this study, data collected from 2008 to 2011 through the KNHANES were used. The target population of the KNHANES included all non-institutionalized Korean civilians of at least 1 year of age. A stratified multi-stage probability sampling design was used. The subjects were selected from sampling units predicated on geographical area, sex, and age, determined by using household registries. Each population group was assigned a weighted value based on geographical and demographic characteristics to allow estimates to be calculated for the entirety of the Korean population. KNHANES is composed of three components surveys: a health interview, heath examination and nutrition survey. The health interview and health examination are performed by trained medical staff and interviewers at the mobile examination center. One week after the health interview and health examination surveys, dieticians visit the home of participants for the nutrition survey. The surveys collect detailed information on socioeconomic status, health behaviours, quality of life, healthcare utilization, anthropometric measures, biochemical profiles using fasting blood serum and urine, measures for dental health, vision, hearing and bone density, X-ray test results, food intake and dietary behavior. The overall response rate was $76.1 \%$ for the heath interview and examination survey and $82.4 \%$ for the nutrition survey. KNHANES data are valuable sources for monitoring changes in risk factors and diseases and identifying target groups in need of interventions. Korea Centers for Disease Control and Prevention (KCDC) and related academic societies have managed external quality control programmes for all steps (including survey administration, data collection, laboratory analysis and data processing) as well as internal quality assurance and control procedures [17]. The questionnaires used in this study included questions that addressed the demographic, socioeconomic, dietary, and medical history of each respondent [18]. After excluding 9882 subjects younger than 20 years of age and 1777 subjects without information on PA, 26,294 subjects consisting of 11,213 male subjects (42.6\%) and 15,081 female subjects $(57.4 \%)$ were included in our final analysis. The Korea Centers for Disease Control and Prevention (KCDC) Institutional Review Board approved the survey protocol, and all participants provided written informed consent. However, this study did not require any ethics approval, because the KNHANES data are publicly available.

\section{Definition of PA}

The IPAQ-SF is used to estimate the overall PA level of an individual in metabolic equivalent (MET)-min/week by determining the duration (in minutes) and number of days (in 1 week) of engagement in three specific types of activity (walking, moderate-intensity activities, and highintensity activities) across a comprehensive set of domains (leisure time, work-related and transport-related physical activities, and domestic and gardening activities) in the past 7 days. The IPAQ-SF has acceptable reliability and validity $[16,19]$ in previous studies. Walking fast, carrying light loads, bicycling at a regular pace, golf or tennis are including in moderate intensity activities and heavy lifting (more than $20 \mathrm{~kg}$ ), digging, aerobics, basketball, swimming or fast bicycling are including in high-intensity 
activities. MET is a unit that is used to estimate the amount of oxygen used by the body during PA. MET$\mathrm{min} /$ week is computed by multiplying the MET score of an activity (3.3 for walking, 4.0 for moderate-intensity activities, and 8.0 for vigorous intensity activities) to the minutes and days (or sessions) of engagement. Respondents were classified according to three PA levels, namely low, moderate, or high, according to the cutoff total MET$\mathrm{min} /$ week in each category [20] as follows:

\section{Category 1 Low}

Individuals who did not meet the criteria for Categories 2 (moderately active) and 3 (highly active) were considered to have low PA levels or as physically inactive.

Category 2 Moderate

a) Three or more days of vigorous-intensity activities of at least $20 \mathrm{~min} /$ day;

b) Five or more days of moderate-intensity activities and/or walking of at least $30 \mathrm{~min} /$ day; or

c) Five or more days of any combination of walking, moderate-intensity activities, and vigorous-intensity activities that could attain a minimum total PA of at least $600 \mathrm{MET}$-min/week.

Category 3 High

a) Vigorous-intensity activities for at least 3 days that could attain a minimum total PA of at least 1500 MET-min/week; or

b) Seven or more days of any combination of walking, moderate-intensity activities, or vigorous-intensity activities that could attain a minimum total PA of at least $3000 \mathrm{MET}$-min/week.

\section{Definition of sarcopenia, obesity, and metabolic syndrome}

Appendicular skeletal muscle mass (ASM) was measured by using dual-energy X-ray absorptiometry (QDR 4500A; Hologic Inc.). ASM (in kilograms) was defined as the sum of the lean soft tissue masses of the arms and legs [21]. To define sarcopenia, we assessed ASM as a percentage of body weight (ASM/weight [Wt.]), which was modified from the method used in the study by Janssen et al [22], and defined as $<2$ SD below the sex-specific mean for a young reference group from the data sets of the 2008 and 2011 KNHANES (960 male subjects and 1240 female subjects, 20-30 years old). The cutoff point for sarcopenia was $29.0 \%$ for male subjects and $22.9 \%$ for female subjects.

The International Obesity Task Force (IOTF) and World Health Organization (WHO) regional office for the Western Pacific region recommend defining obesity in Asians as a BMI of $\geq 25 \mathrm{~kg} / \mathrm{m}^{2}$. Subsequently, the Korean Society for the Study of Obesity (KSSO) adopted this definition [23]. Thus, subjects were classified as obese if their BMIs were $\geq 25 \mathrm{~kg} / \mathrm{m}^{2}$ according to the standards of the IOTF, WHO, and KSSO.

The modified National Cholesterol Education Program's Adult Treatment Panel III (NCEP ATP III) Asian criteria for metabolic syndrome was used, requiring 3 or more of the following criteria: WC, $\geq 90 \mathrm{~cm}$ for male subjects and $\geq 85 \mathrm{~cm}$ for female subjects [24]; triglyceride level, $\geq 150 \mathrm{mg} / \mathrm{dl}$; high-density lipoprotein (HDL)-cholesterol level, $\leq 40 \mathrm{mg} / \mathrm{dl}$ for male subjects and $\leq 50 \mathrm{mg} / \mathrm{dl}$ for female subjects; blood pressure, $\geq 130 / 85 \mathrm{~mm} \mathrm{Hg}$; and fasting glucose level, $\geq 100 \mathrm{mg} / \mathrm{dl}$.

\section{Definition of CVD}

CVD was defined as previous cardiovascular events such as angina pectoris, myocardial infarction, and stroke [25]. We also included chronic renal disease, which was defined as chronic kidney disease stage $\geq 3$ (glomerular filtration rate [GFR] of $\geq 60 \mathrm{ml} / \mathrm{min} / 1.73 \mathrm{~m}^{2}$ ) in CVD $[26,27]$. GFR was estimated by using the Modification of Diet in Renal Disease (MDRD) equation.

\section{Statistical analyses}

All data were expressed as number and percentage (\%) or mean \pm standard deviation. Continuous variables were compared by using an independent $t$ test or analysis of variance. Categorical variables were compared by using the chi-square test or Fisher exact test. The odds ratio (OR) for stroke, myocardial infarction, angina pectoris, and chronic renal disease according to physical groups were calculated by using logistic regression. The multivariable-adjusted model was adjusted for known confounding factors such as age, sex, hypertension, DM, and smoking. $P$ values of $<0.05$ were considered statistically significant. The Statistical Package for the Social Sciences (SPSS, version 19; SPSS, Chicago, IL, USA) was used for these analyses.

\section{Results}

Table 1 shows the baseline characteristics of the participants according to their activity levels. Low, moderate, and high activity groups comprised 20.2, 45.6, and $34.2 \%$ of the study population, respectively. Older and female subjects were more prevalent in the low activity group. Resting heart rate was lower in the high activity group than in low or moderate activity group. Serum concentrations of fasting glucose (low $>$ moderate $=$ high activity group, $p=0.001)$, alkaline phosphatase (low $>$ moderate $=$ high activity group, $p=0.001$ ), parathyroid hormone (low $>$ moderate $>$ high activity group, $p=0.001$ ), ferritin (low $>$ moderate $>$ high activity group, $p=0.001$ ) were highest, but vitamin $\mathrm{D}$ level was lowest in the low activity group. The associations between clinical measures of body composition and PA are summarized in Table 2. ASM was higher in the high activity 
Table 1 Subject characteristics according to physical activity levels

\begin{tabular}{|c|c|c|c|c|}
\hline & $\begin{array}{l}\text { Low } \\
(n=5309) \\
(20.2 \%)\end{array}$ & $\begin{array}{l}\text { Moderate } \\
(n=11,997) \\
(45.6 \%)\end{array}$ & $\begin{array}{l}\text { High } \\
(n=8988) \\
(34.2 \%)\end{array}$ & $P$-value \\
\hline Age (years) & $a_{53} \pm 17$ & ${ }^{b} 49 \pm 16$ & $\mathrm{~b}_{49} \pm 15$ & 0.001 \\
\hline Male & $1951(36.7)$ & $4651(38.8)$ & $4611(51.3)$ & 0.001 \\
\hline Hypertension & 2099 (39.5) & 4155 (34.6) & $3142(35.0)$ & 0.001 \\
\hline Diabetes mellitus & $669(12.6)$ & $1302(10.9)$ & $1074(11.9)$ & 0.002 \\
\hline Dyslipidemia & $488(9.2)$ & $1168(9.7)$ & $821(9.1)$ & 0.283 \\
\hline Current smoker & $1573(29.6)$ & $3471(28.9)$ & $3431(38.1)$ & 0.001 \\
\hline Systolic blood pressure (mm Hg) & ${ }^{\mathrm{a}} 120 \pm 18$ & $b_{118} \pm 18$ & ${ }^{c} 119 \pm 17$ & 0.001 \\
\hline Diastolic blood pressure $(\mathrm{mm} \mathrm{Hg})$ & ${ }^{a} 76 \pm 11$ & $b_{76} \pm 11$ & $b_{77} \pm 11$ & 0.001 \\
\hline Resting heart rate & $\mathrm{a}_{71} \pm 10$ & $\mathrm{a} 70 \pm 9$ & $\mathrm{~b}_{69} 09$ & 0.001 \\
\hline Hemoglobin (mg/dl) & ${ }^{\mathrm{a}} 13.7 \pm 1.6$ & ${ }^{\mathrm{a}} 13.8 \pm 1.6$ & $b_{14.1} \pm 1.6$ & 0.002 \\
\hline Creatinine (mg/dl) & $0.8 \pm 0.3$ & $0.8 \pm 0.2$ & $0.8 \pm 0.2$ & 0.323 \\
\hline Fasting glucose (mg/dl) & a $99.1 \pm 26.9$ & b $97.5 \pm 22.4$ & b $97.9 \pm 22.8$ & 0.001 \\
\hline $25(\mathrm{OH})$ vitamin $\mathrm{D}_{3}(\mathrm{ng} / \mathrm{mL})$ & ${ }^{a} 17.5 \pm 6.5$ & ${ }^{b} 17.9 \pm 6.5$ & ${ }^{c} 19.5 \pm 7.0$ & 0.001 \\
\hline PTH (pg/ml) & a $71.3 \pm 37.1$ & ${ }^{b} 67.5 \pm 29.6$ & ${ }^{c} 65.2 \pm 26.3$ & 0.001 \\
\hline Ferritin (ng/mL) & a $82.7 \pm 104.8$ & $b_{81.2 \pm 110.4}$ & ${ }^{c} 80.4 \pm 123.7$ & 0.001 \\
\hline ALP (U/L) & ${ }^{\mathrm{a}} 231.3 \pm 75.9$ & ${ }^{b} 223.4 \pm 76.6$ & ${ }^{b} 224.8 \pm 69.3$ & 0.001 \\
\hline Triglyceride (mg/dl) & $\mathrm{a}_{137.3 \pm 106.5}$ & ${ }^{b} 133.4 \pm 105.1$ & ${ }^{b} 134.0 \pm 118.0$ & 0.101 \\
\hline HDL-cholesterol (mg/dl) & $\mathrm{a}_{51.5} \pm 12.5$ & $b_{52.3 \pm 12.7}$ & $b_{52.7 \pm 13.0}$ & 0.004 \\
\hline
\end{tabular}

ALP alkaline phosphatase, $H D L$ high-density lipoprotein, 25(OH)D 25-dihydroxyvitamin D; PTH = parathyroid hormone

Values were represented as mean \pm standard deviation, or $\mathrm{n}(\%)$

$\mathrm{a}, \mathrm{b},{ }^{c}$ were designated according to post hoc analysis. Same marker was used to represent no statistically significant difference

Table 2 Body composition and metabolic syndrome components according to physical activity level

\begin{tabular}{|c|c|c|c|c|}
\hline & $\begin{array}{l}\text { LOW } \\
(n=5309) \\
(20.2 \%)\end{array}$ & $\begin{array}{l}\text { Moderate } \\
(n=11,997) \\
(45.6 \%)\end{array}$ & $\begin{array}{l}\text { High } \\
(n=8988) \\
(34.2 \%)\end{array}$ & $p$ value \\
\hline ASM (kg) & $17.1 \pm 4.6$ & $17.7 \pm 4.7$ & $19.2 \pm 4.9$ & 0.001 \\
\hline ASM/weight (\%) & $18.9 \pm 13.7$ & $20.2 \pm 13.5$ & $21.7 \pm 13.9$ & 0.001 \\
\hline Sarcopenia & 509 (14.3) & $892(10.5)$ & $477(7.3)$ & 0.001 \\
\hline $\mathrm{BMI}>25 \mathrm{~kg} / \mathrm{m}^{2}$ & $260(4.9)$ & $539(4.5)$ & $441(4.9)$ & 0.289 \\
\hline $\mathrm{BMI}<18.5 \mathrm{~kg} / \mathrm{m}^{2}$ & $301(5.7)$ & $587(4.9)$ & $311(3.5)$ & 0.001 \\
\hline Sarcopenic obesity & $157(4.4)$ & $321(3.8)$ & $252(3.9)$ & 0.274 \\
\hline Metabolic syndrome & $428(8.1)$ & $846(7.1)$ & $645(7.2)$ & 0.054 \\
\hline${ }^{\mathrm{a} C e n t r a l}$ obesity & $413(7.8)$ & $823(6.9)$ & $564(6.3)$ & 0.002 \\
\hline High triglyceride & $1515(30.6)$ & $3292(28.7)$ & $2453(28.1)$ & 0.006 \\
\hline Low HDL & $1667(33.7)$ & 3558 (31.0) & 2324 (26.6) & 0.001 \\
\hline Hypertension & $2099(39.5)$ & 4155 (34.6) & $3142(35.0)$ & 0.001 \\
\hline Diabetes mellitus & 669 (12.6) & 1302 (10.9) & 1074 (11.9) & 0.002 \\
\hline
\end{tabular}

ASM appendicular skeletal muscle mass, BMI body mass index,

$H D L$ high-density lipoprotein

${ }^{a}$ Waist circumference of $\geq 90 \mathrm{~cm}$ for male subjects and $\geq 85 \mathrm{~cm}$ for female subjects group (high $>$ moderate $=$ low activity group, $p=0.001$ ) . Obesity measure according to BMI did not differ between the groups, but sarcopenia had an inverse relationship with PA level (OR in moderate activity $=0.744$, OR in high activity $=0.516$, both compared with low activity group, $p=0.001$ ). Each metabolic syndrome component was also associated with PA level, and the risk of metabolic syndrome was higher in the low activity group.

The ORs for the prevalence of CVD, as calculated by using logistic regression analyses, are shown in Table 3. On the univariate analysis, the prevalence of CVD was significantly lower in the moderate $(\mathrm{OR}=0.722, p=0.001)$ or high activity group (OR $=0.610, p=0.001$ ) than in the low activity group. This difference in prevalence remained significant after adjustment for conventional risk factors of CVD, including age, HTN, DM, smoking, and male sex. Besides PA level, sarcopenia, BMI, and central obesity were associated with the prevalence of CVD (Table 3).

Then, we performed a multivariate logistic analysis in order to adjust for the body composition parameters and metabolic risk components, which were regarded as independent risk factors of CVD. In the comparison between high or moderate activity group and the low activity group, the odds ratio was still significant after adjustment for each variable, except for sarcopenia, which showed a difference only between the high and low 
Table 3 Odds ratio of cardiovascular disease (MI, stable angina, stroke, and chronic renal disease) according to physical activity, body composition, and metabolic syndrome component

\begin{tabular}{|c|c|c|c|c|}
\hline & \multicolumn{2}{|l|}{ Non-adjusted } & \multicolumn{2}{|l|}{${ }^{\mathrm{b}}$ Adjusted } \\
\hline & Odds ratio ( $95 \%$ confidence interval) & $p$ value & Odds ratio ( $95 \%$ confidence interval) & $p$ value \\
\hline \multicolumn{5}{|l|}{ Activity } \\
\hline Low & 1 & & & \\
\hline Moderate & $0.72(0.65-0.80)$ & 0.001 & $0.82(0.74-0.92)$ & 0.001 \\
\hline High & $0.61(0.55-0.68)$ & 0.001 & $0.66(0.59-0.75)$ & 0.001 \\
\hline Sarcopenia & $2.17(1.95-2.43)$ & 0.001 & $1.63(1.45-1.84)$ & 0.001 \\
\hline $\mathrm{BMI}>25 \mathrm{~kg} / \mathrm{m}^{2}$ & $1.32(1.10-1.57)$ & 0.003 & $1.30(1.08-1.57)$ & 0.005 \\
\hline${ }^{\mathrm{a}}$ Central obesity & $2.40(2.11-2.72)$ & 0.001 & $1.82(1.59-2.08)$ & 0.001 \\
\hline High triglyceride & $1.58(1.45-1.73)$ & 0.001 & $1.21(1.10-1.33)$ & 0.001 \\
\hline Low HDL & $1.64(1.50-1.79)$ & 0.001 & $1.58(1.44-1.74)$ & 0.001 \\
\hline
\end{tabular}

$B M I$ body mass index, $H D L$ high-density lipoprotein, $M I$ myocardial infarction

${ }^{a}$ Waist circumference of $\geq 90 \mathrm{~cm}$ for male subjects and $\geq 85 \mathrm{~cm}$ for female subjects

${ }^{b}$ Adjusted variables: age of $>65$ years, hypertension, diabetes mellitus, sex, and smoking

activity groups (Table 4). Figure 1 shows that each CVD component including stroke, coronary heart disease and chronic renal failure also had an inverse relationship with PA level, and Fig. 2 demonstrates a dose-response relationship between PA level and CVD prevalence and it is more prominent in female group.

\section{Discussion}

The main findings of this study were as follows: 1) the prevalence rates of HTN, DM, and resting heart rate were lower in the moderate or high activity group than in the low activity group; 2 ) the moderate or high activity group had more balanced body composition and lower risk of metabolic syndrome components, including HDL and TG level; 3) PA was associated with a lower prevalence of CVD, and this association remained after adjustment for the potential confounding factors (age, sex, smoking, HTN, and DM), and body composition parameters and metabolic syndrome components (muscle mass, BMI, central obesity, low HDL level, and high triglyceride level).

In 1953, Morris et al. [28] first reported the association between PA and protection against CVD. Since then, many other studies have been conducted and have yielded similar results. The PA guidelines for Americans that were published in 2008 recommend that $150 \mathrm{~min} /$ week of moderate-intensity aerobic PA or $75 \mathrm{~min} /$ week of vigorous-intensity aerobic PA is associated with protection from CVD [14]. Although the precise mechanisms of the reduced risk of CVD associated with PA are not well understood, reductions in the traditional risk factors, including blood pressure, BMI, glucose abnormalities [16, 29], and the chronic anti-inflammatory effect, mediated by PA were proposed as possible mechanisms [13]. However, most prospective cohort studies that used self-reported data on PA to examine its association with CVD risk were published in Western countries [15], and PA and its association with body composition or CVD varies with race and lifestyle. In accordance with previous studies, the prevalence rates of HTN and DM and fasting glucose level were higher in the low activity group than in the moderate or high group. Resting heart rate was lower in the high activity group than in the low or moderate group. In previous studies, elevated resting heart rate was associated with

Table 4 Association of physical activity level with CVD after adjustment for data sets of potential mediators

\begin{tabular}{|c|c|c|c|c|c|}
\hline & Low & Moderate & $p$ value & High & $p$ value \\
\hline Age of $>65$ years and sex & 1.00 & $0.82(0.71-0.95)$ & 0.001 & $0.678(0.58-0.80)$ & 0.001 \\
\hline Basic model $^{a}$ & 1.00 & $0.82(0.74-0.92)$ & 0.029 & $0.66(0.59-0.75)$ & 0.001 \\
\hline \multicolumn{6}{|c|}{ Basic model plus each set of risk factors below } \\
\hline $\mathrm{BMI}>25 \mathrm{~kg} / \mathrm{m}^{2}$ & 1.00 & $0.82(0.71-0.95)$ & 0.025 & $0.67(0.57-0.79)$ & 0.001 \\
\hline Sarcopenia & 1.00 & $0.87(0.73-1.05)$ & 0.287 & $0.75(0.61-0.92)$ & 0.005 \\
\hline Central obesity & 1.00 & $0.83(0.71-0.96)$ & 0.031 & $0.68(0.57-0.80)$ & 0.014 \\
\hline High triglyceride & 1.00 & $0.81(0.70-0.95)$ & 0.029 & $0.70(0.59-0.83)$ & 0.001 \\
\hline Low HDL & 1.00 & $0.81(0.70-0.95)$ & 0.029 & $0.71(0.60-0.84)$ & 0.001 \\
\hline
\end{tabular}

$B M I$ body mass index, CVD cardiovascular disease

${ }^{\mathrm{a} A g e, ~ s e x, ~ s m o k i n g, ~ h y p e r t e n s i o n, ~ a n d ~ d i a b e t e s ~ m e l l i t u s ~}$ 


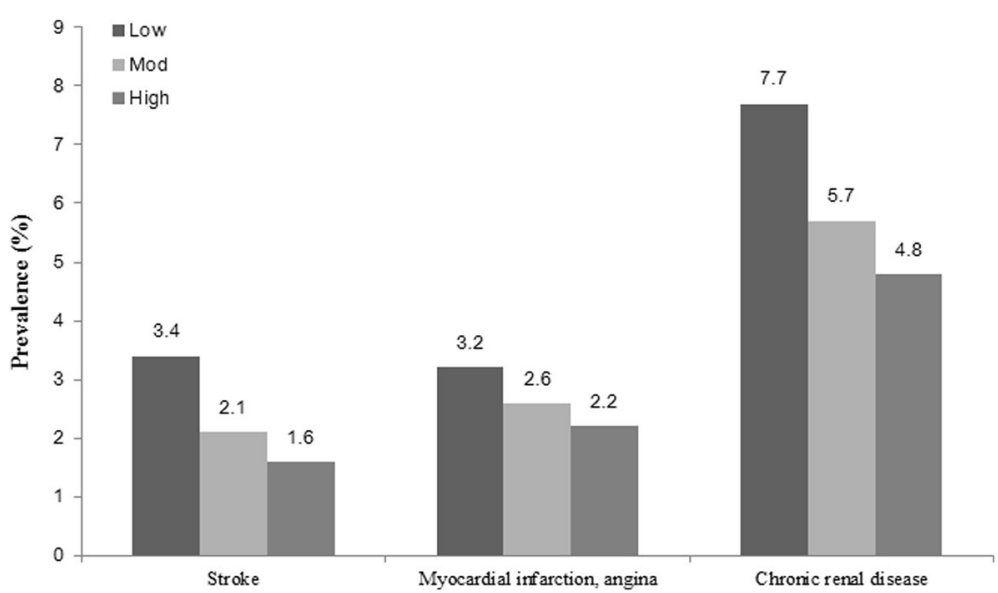

Fig. 1 Prevalence of cardiovascular disease according to physical activity

metabolic syndrome and poor outcome in patients with heart failure or coronary heart disease [30,31]. It is interesting that the levels of biomarkers such as vitamin $\mathrm{D}$, serum ferritin, ALP, and PTH differed according to PA level, as shown in Table 1. Vitamin D deficiency and elevated levels of ALP, ferritin, and PTH were identified as predictors of metabolic syndrome or poor prognosis of CVD in previous studies [32-35]. Thus, the favorable effect of PA on the prevalence of CVD might have relevance to these biomarkers, and further prospective studies are needed.

The moderate or high activity group had significantly lower prevalence rates of sarcopenia, underweight, and abdominal obesity, whereas no significant difference was observed in general obesity defined as a BMI of $\geq 25 \mathrm{~kg} / \mathrm{m}^{2}$. From these findings, we can infer that regular PA does not simply reduce weight but should be coupled with more balanced body composition and physical fitness, as sarcopenia, central obesity, and underweight were reported as independent risk factors of developing CVD and mortality or poor prognosis in patients with CVD and general obesity [36-41]. Analysis of the association between PA and CVD revealed a positive dose-response relationship, with an OR of 0.822 (95\% CI, 0.737-0.916) for the moderate group and $0.663(0.589-0.748)$ for the high group. In IPAQ scale, strength trainings such as digging, heavy lifting or fast bicycling are included in moderate to high intensity activities. These activities strengthen and maintain lean muscle mass as well as burning calories. Previous studies reported that muscle mass is associated with cardiovascular risk, prevalence of cardiovascular disease and insulin resistance [42-45]. Thus, in line with previous studies, the results of this study also showed strength trainings assessed by IPAQ scale is associated with physical fitness and lower prevalence of CVD. These risk reduction remained significant even after adjusting for conventional risk factors of CVD, including age, HTN, DM, sex, and

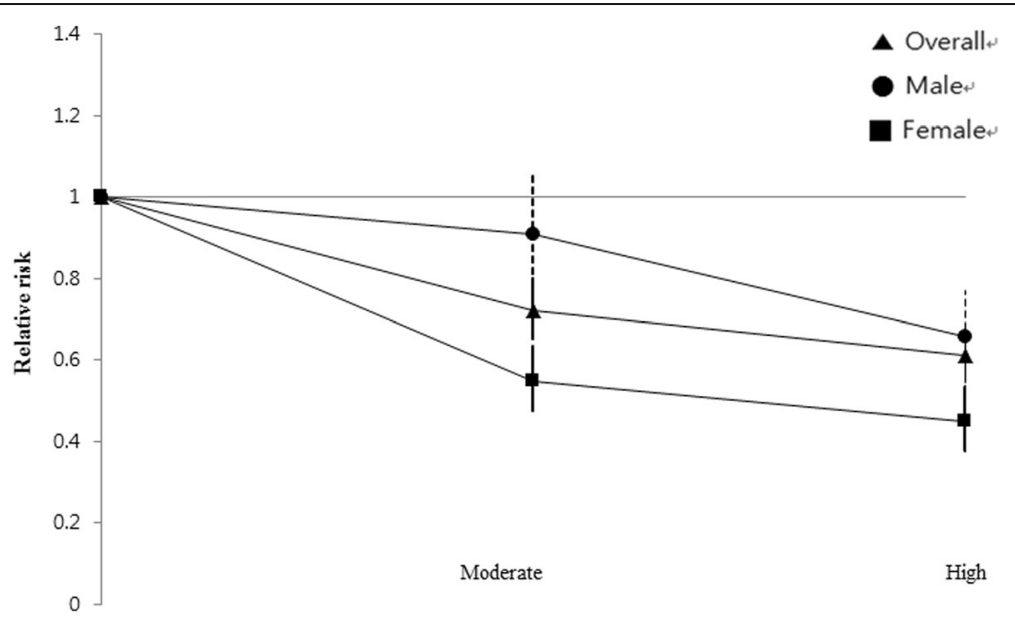

Fig. 2 Relative risk of CVD according to physical activity 
smoking. A dose-response relationship was difficult to define because of the different questionnaires used across various studies to assess PA in 1 or more domains of activity (leisure-time, household, occupation, and commuting activity), with most of the studies assessing primarily leisure-time PA [15]. In our study, we used the IPAQ as mentioned earlier, and the classification of PA was similar with the definition in the 2008 American guidelines [14], which defined "moderate" as at least $150 \mathrm{~min} /$ week of moderate-intensity activity or $75 \mathrm{~min} /$ week of vigorous activity and "high" as $300 \mathrm{~min} /$ week of moderate-intensity activity or $150 \mathrm{~min} /$ week of vigorous activity. Previous studies that were based on assessments according to the 2008 guidelines reported that the moderate- and high-intensity groups had $20-25 \%$ and $30-35 \%$ reduction in the risk of CVD $[12,13,46]$. These results approximately equal our data, as the risk reduction rates were 28 and $34 \%$ in the moderate and high groups, respectively. Furthermore, the OR was more significant in the female subjects than in the male subjects, as shown in Fig. 2, concurring with the results of previous studies that reported a median risk reduction of $40 \%$ in female subjects and $30 \%$ in male subjects [47-50]. Thus, the dose-response relationship and prominent effect of PA in female subjects were observed in the Asian population. Considering of these clear relationship with IPAQ scale and physical fitness and clinical outcome, IPAQ could be used as a reliable questionnaire to assess physical activity in patients with high risk of CVD event including patients with diabetes, obesity and metabolic syndrome.

To further understand the association between PA level and CVD, an additional logistic analysis was conducted after combining PA with the conventional risk factors and body composition parameters (Table 4). After adjusting for these factors, the relationship in the moderate or high activity group remained significant. Whether higher PA level mitigate the risk of CVD associated with being overweight or obese is controversial [51-53]. Our results show that PA level has a strong association with the prevalence of CVD, independent of body composition, including both general and central obesities and other conventional risk factors of CVD.

Some limitations should be considered in the interpretation of this study. First, it used a cross-sectional design, which limited the ability to detect causal relationships. Therefore, the cause-and-effect relationships of PA level with cardiometabolic risk factors and prevalence of CVD cannot be precisely inferred, although this study included a representative sample of the general Korean population. Second, this study was based on data obtained by using the IPAQ-short form for PA level. Thus, we could not fully exclude the effects of information bias. Third, although all participants were initially evaluated the heath interview and heath examination at the mobile examination center (bus) which means at least they were able to ambulate, it is impossible to fully exclude the possibility of reverse causation of the association between PA and CVD. It means that our results confined the relationship between the PA and prevalence of CVD not causal relationship of them. Thus, further randomized controlled trials regarding the incidence of CVD according to PA are necessary.

\section{Conclusions}

In conclusion, moderate or high PA level was associated with a low prevalence of CVD (stroke, myocardial infarction, stable angina, and chronic renal disease), which was independent of body composition (general or central obesity, and sarcopenia) and conventional risk factors in the Korean population. Furthermore, the dose-response relationship between PA level and the prevalence of CVD, and the more-prominent effect in female subjects were in line with those in previous studies conducted in the Western population.

\section{Abbreviations \\ BMI: Body mass index; CVD: Cardiovascular disease; DM: Diabetes mellitus; HTN: Hypertension; IPAQ: International physical activity questionnaire; KNHANES: Korean national health and nutrition examination survey; MET: Metabolic equivalent; PA: Physical activity; WC: Waist circumference}

\section{Acknowledgements}

N/A.

Funding

None received for the study.

Availability of data and materials

The dataset is freely available for public use on www.knhanes.cdc.go.kr.

Authors' contributions

GS-K: Conception and design, drafting the manuscript. El: Conception and design, revising manuscript. JH-R: Conception and design, revising and final approval of final version. All authors read and approved the final manuscript.

Competing interests

We declare that we have no financial competing interests or non-financial competing interests.

\section{Consent for publication}

N/A.

Ethics approval and consent to participate

The Korea Centers for Disease Control and Prevention (KCDC) Institutional Review Board approved the survey protocol, and all participants provided written informed consent. However, this study did not require any ethics approval, because the KNHANES data are publicly available.

\section{Author details}

'Division of Cardiology, Department of Internal Medicine, Sanggye Paik Hospital, Inje University College of Medicine, Seoul, Republic of Korea. ${ }^{2}$ Division of Cardiology, Department of Internal Medicine, Yongin Severance Hospital, Yonsei University College of Medicine, Yongin, Republic of Korea. ${ }^{3}$ Division of Cardiology, Yongin Severance Hospital, Yonsei University College of Medicine, 225 Geumhak-ro, Cheoin-gu, Yongin 17046, South Korea. 


\section{Received: 19 April 2016 Accepted: 13 February 2017} Published online: 21 March 2017

\section{References}

1. Vilahur G, Badimon JJ, Bugiardini R, Badimon L. Perspectives: The burden of cardiovascular risk factors and coronary heart disease in Europe and worldwide. Eur Heart J Suppl. 2014;16(suppl A):A7-A11.

2. Lozano R, Naghavi M, Foreman K, Lim S, Shibuya K, Aboyans V, Abraham J, Adair T, Aggarwal R, Ahn SY, et al. Global and regional mortality from 235 causes of death for 20 age groups in 1990 and 2010: a systematic analysis for the Global Burden of Disease Study 2010. Lancet. 2012;380(9859):2095-128.

3. Saha S, Gerdtham UG, Johansson P. Economic evaluation of lifestyle interventions for preventing diabetes and cardiovascular diseases. Int $J$ Environ Res Public Health. 2010;7(8):3150-95.

4. Gaziano TA, Galea G, Reddy KS. Scaling up interventions for chronic disease prevention: the evidence. Lancet. 2007;370(9603):1939-46.

5. Haskell WL. Cardiovascular disease prevention and lifestyle interventions: effectiveness and efficacy. J Cardiovasc Nurs. 2003;18(4):245-55.

6. Groeneveld IF, Proper Kl, van der Beek AJ, Hildebrandt VH, van Mechelen W. Lifestyle-focused interventions at the workplace to reduce the risk of cardiovascular disease - a systematic review. Scand J Work Environ Health. 2010;36(3):202-15

7. Banta HD, de Wit GA. Public health services and cost-effectiveness analysis. Annu Rev Public Health. 2008;29:383-97.

8. Booth 3rd JN, Levitan EB, Brown TM, Farkouh ME, Safford MM, Muntner P. Effect of sustaining lifestyle modifications (nonsmoking, weight reduction, physical activity, and mediterranean diet) after healing of myocardial infarction, percutaneous intervention, or coronary bypass (from the REasons for Geographic and Racial Differences in Stroke Study). Am J Cardiol. 2014; 113(12):1933-40.

9. Sofi F, Capalbo A, Cesari F, Abbate R, Gensini GF. Physical activity during leisure time and primary prevention of coronary heart disease: an updated meta-analysis of cohort studies. Eur J Cardiovasc Prev Rehabil. 2008;15(3): 247-57

10. Nocon M, Hiemann T, Muller-Riemenschneider F, Thalau F, Roll S, Willich SN Association of physical activity with all-cause and cardiovascular mortality: a systematic review and meta-analysis. Eur J Cardiovasc Prev Rehabil. 2008; 15(3):239-46.

11. Manson JE, Greenland P, LaCroix AZ, Stefanick ML, Mouton CP, Oberman A, Perri MG, Sheps DS, Pettinger MB, Siscovick DS. Walking compared with vigorous exercise for the prevention of cardiovascular events in women. $\mathrm{N}$ Engl J Med. 2002;347(10):716-25.

12. Smith TC, Wingard DL, Smith B, Kritz-Silverstein D, Barrett-Connor E. Walking decreased risk of cardiovascular disease mortality in older adults with diabetes. J Clin Epidemiol. 2007;60(3):309-17.

13. Mora S, Cook N, Buring JE, Ridker PM, Lee IM. Physical activity and reduced risk of cardiovascular events: potential mediating mechanisms. Circulation. 2007:116(19):2110-8

14. 2008 Physical Activity Guidelines for Americans. US Department of Health and Human Services. http://www.health.gov/paguidelines/. Accessed 16 Jan 2010.

15. Shiroma EJ, Lee IM. Physical activity and cardiovascular health: lessons learned from epidemiological studies across age, gender, and race/ethnicity. Circulation. 2010;122(7):743-52.

16. Craig $C L$, Marshall $A L$, Sjostrom M, Bauman AE, Booth ML, Ainsworth BE, Pratt M, Ekelund U, Yngve A, Sallis JF, et al. International physical activity questionnaire: 12-country reliability and validity. Med Sci Sports Exerc. 2003; 35(8):1381-95.

17. Kweon S, Kim Y, Jang MJ, Kim Y, Kim K, Choi S, Chun C, Khang YH, Oh K. Data resource profile: the Korea National Health and Nutrition Examination Survey (KNHANES). Int J Epidemiol. 2014;43(1):69-77.

18. KNHANES. KNHANES statistical information. Available at http://knhanes.cdc. go.kr/. Accessed on 20 Aug 2010

19. Kurtze N, Rangul V, Hustvedt BE. Reliability and validity of the international physical activity questionnaire in the Nord-Trondelag health study (HUNT) population of men. BMC Med Res Methodol. 2008:8:63.

20. IPAQ Research Committee. International physical activity questionnaire. https://sites.google.com/site/theipaq/scoring-protocol. Accessed 30 July 2016.

21. Heymsfield SB, Smith R, Aulet M, Bensen B, Lichtman S, Wang J, Pierson Jr RN. Appendicular skeletal muscle mass: measurement by dual-photon absorptiometry. Am J Clin Nutr. 1990;52(2):214-8.
22. Janssen I, Heymsfield SB, Ross R. Low relative skeletal muscle mass (sarcopenia) in older persons is associated with functional impairment and physical disability. J Am Geriatr Soc. 2002;50(5):889-96.

23. Oh SW. Obesity and metabolic syndrome in Korea. Diabetes Metab J. 2011 ; 35(6):561-6

24. Lee SY, Park HS, Kim DJ, Han JH, Kim SM, Cho GJ, Kim DY, Kwon HS, Kim SR, Lee CB, et al. Appropriate waist circumference cutoff points for centra obesity in Korean adults. Diabetes Res Clin Pract. 2007;75(1):72-80.

25. Mancia G, De Backer G, Dominiczak A, Cifkova R, Fagard R, Germano G, Grassi G, Heagerty AM, Kjeldsen SE, Laurent S, et al. 2007 Guidelines for the Management of Arterial Hypertension: The Task Force for the Management of Arterial Hypertension of the European Society of Hypertension (ESH) and of the European Society of Cardiology (ESC). J Hypertens. 2007;25(6):1105-87.

26. Vanholder R. Chronic kidney disease in adults - UK guidelines for identification, management and referral. Nephrol Dial Transplant. 2006:21(7):1776-7.

27. Lee SR, Cha MJ, Kang DY, Oh KC, Shin DH, Lee HY. Increased prevalence of metabolic syndrome among hypertensive population: ten years' trend of the Korean National Health and Nutrition Examination Survey. Int J Cardiol. 2013:166(3):633-9.

28. Morris JN, Heady JA, Raffle PA, Roberts CG, Parks JW. Coronary heart-disease and physical activity of work. Lancet. 1953;265(6795):1053-7. contd.

29. Jakicic JM, Marcus BH, Gallagher Kl, Napolitano M, Lang W. Effect of exercise duration and intensity on weight loss in overweight, sedentary women: a randomized trial. JAMA. 2003;290(10):1323-30.

30. Yang HI, Kim HC, Jeon JY. The association of resting heart rate with diabetes, hypertension, and metabolic syndrome in the Korean adult population: The fifth Korea national health and nutrition examination survey. Clin Chim Acta. 2016:455:195-200.

31. Bohm M, Robertson M, Borer J, Ford I, Komajda M, Mahfoud F, Ewen S, Swedberg K, Tavazzi L. Effect of Visit-to-Visit Variation of Heart Rate and Systolic Blood Pressure on Outcomes in Chronic Systolic Heart Failure: Results From the Systolic Heart Failure Treatment With the If Inhibitor Ivabradine Trial (SHIFT) Trial. J Am Heart Assoc. 2016;5(2):e002160.

32. Wang TJ, Pencina MJ, Booth SL, Jacques PF, Ingelsson E, Lanier K, Benjamin EJ, D'Agostino RB, Wolf M, Vasan RS. Vitamin D deficiency and risk of cardiovascular disease. Circulation. 2008;117(4):503-11.

33. Hagstrom E, Ahlstrom T, Arnlov J, Larsson A, Melhus H, Hellman P, Lind L. Parathyroid hormone and calcium are independently associated with subclinical vascular disease in a community-based cohort. Atherosclerosis. 2015;238(2):420-6.

34. Felipe A, Guadalupe E, Druso P, Carlos M, Pablo S, Oscar C, Luis V, Diego M, Jaime R, Ines U, et al. Serum Ferritin Is Associated with Metabolic Syndrome and Red Meat Consumption. Oxidative Med Cell Longev. 2015;2015:769739.

35. Cheung BM, Ong KL, Wong LY. Elevated serum alkaline phosphatase and peripheral arterial disease in the United States National Health and Nutrition Examination Survey 1999-2004. Int J Cardiol. 2009;135(2):156-61.

36. van der Leeuw J, van der Graaf $Y$, Nathoe HM, de Borst GJ, Kappelle LJ, Visseren FL, group Ss. The separate and combined effects of adiposity and cardiometabolic dysfunction on the risk of recurrent cardiovascular events and mortality in patients with manifest vascular disease. Heart. 2014;100(18):1421-9.

37. Myint PK, Kwok CS, Luben RN, Wareham NJ, Khaw KT. Body fat percentage, body mass index and waist-to-hip ratio as predictors of mortality and cardiovascular disease. Heart. 2014;100(20):1613-9.

38. Lavie CJ, Milani RV, Ventura HO. Obesity and cardiovascular disease: risk factor, paradox, and impact of weight loss. J Am Coll Cardiol. 2009:53(21):1925-32

39. Lavie CJ, De Schutter A, Alpert MA, Mehra MR, Milani RV, Ventura HO. Obesity paradox, cachexia, frailty, and heart failure. Heart Fail Clin. 2014;10(2):319-26.

40. Golledge J, Cronin O, lyer V, Bradshaw B, Moxon JV, Cunningham MA. Body mass index is inversely associated with mortality in patients with peripheral vascular disease. Atherosclerosis. 2013;229(2):549-55.

41. Gelber RP, Gaziano JM, Orav EJ, Manson JE, Buring JE, Kurth T. Measures of obesity and cardiovascular risk among men and women. J Am Coll Cardiol. 2008;52(8):605-15.

42. Lee SW, Youm Y, Lee WJ, Choi W, Chu SH, Park YR, Kim HC. Appendicular skeletal muscle mass and insulin resistance in an elderly korean population: the korean social life, health and aging project-health examination cohort. Diabetes Metab J. 2015;39(1):37-45

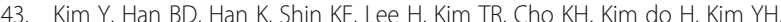
Kim $\mathrm{H}$, et al. Optimal cutoffs for low skeletal muscle mass related to cardiovascular risk in adults: The Korea National Health and Nutrition Examination Survey 2009-2010. Endocrine. 2015;50(2):424-33. 
44. Kim TN, Choi KM. The implications of sarcopenia and sarcopenic obesity on cardiometabolic disease. J Cell Biochem. 2015;1 16(7):1171-8.

45. Kim JH, Cho JJ, Park YS. Relationship between sarcopenic obesity and cardiovascular disease risk as estimated by the Framingham risk score. J Korean Med Sci. 2015;30(3):264-71.

46. van Dam RM, Li T, Spiegelman D, Franco OH, Hu FB. Combined impact of lifestyle factors on mortality: prospective cohort study in US women. BMJ. 2008;337:a1440.

47. Sherman SE, D'Agostino RB, Silbershatz H, Kannel WB. Comparison of past versus recent physical activity in the prevention of premature death and coronary artery disease. Am Heart J. 1999;138(5 Pt 1):900-7.

48. Haapanen N, Miilunpalo S, Vuori I, Oja P, Pasanen M. Association of leisure time physical activity with the risk of coronary heart disease, hypertension and diabetes in middle-aged men and women. Int J Epidemiol. 1997;26(4): 739-47.

49. Folsom AR, Arnett DK, Hutchinson RG, Liao F, Clegg LX, Cooper LS. Physical activity and incidence of coronary heart disease in middle-aged women and men. Med Sci Sports Exerc. 1997;29(7):901-9.

50. Dorn JP, Cerny FJ, Epstein LH, Naughton J, Vena JE, Winkelstein J. W, Schisterman E, Trevisan M. Work and leisure time physical activity and mortality in men and women from a general population sample. Ann Epidemiol. 1999;9(6):366-73.

51. Li TY, Rana JS, Manson JE, Willett WC, Stampfer MJ, Colditz GA, Rexrode KM, Hu FB. Obesity as compared with physical activity in predicting risk of coronary heart disease in women. Circulation. 2006;113(4):499-506.

52. Lee DC, Sui X, Blair SN. Does physical activity ameliorate the health hazards of obesity? Br J Sports Med. 2009;43(1):49-51.

53. Sui X, LaMonte MJ, Laditka JN, Hardin JW, Chase N, Hooker SP, Blair SN. Cardiorespiratory fitness and adiposity as mortality predictors in older adults. JAMA. 2007;298(21):2507-16

\section{Submit your next manuscript to BioMed Central and we will help you at every step:}

- We accept pre-submission inquiries

- Our selector tool helps you to find the most relevant journal

- We provide round the clock customer support

- Convenient online submission

- Thorough peer review

- Inclusion in PubMed and all major indexing services

- Maximum visibility for your research

Submit your manuscript at www.biomedcentral.com/submit

C) Biomed Central 